\title{
AS CIDADES DOS BÓIAS-FRIAS
}

o desdobramento do poder e controle da empresa

Maria A. Moraes Silva*

Foto: Antenor Dalla Vecchia

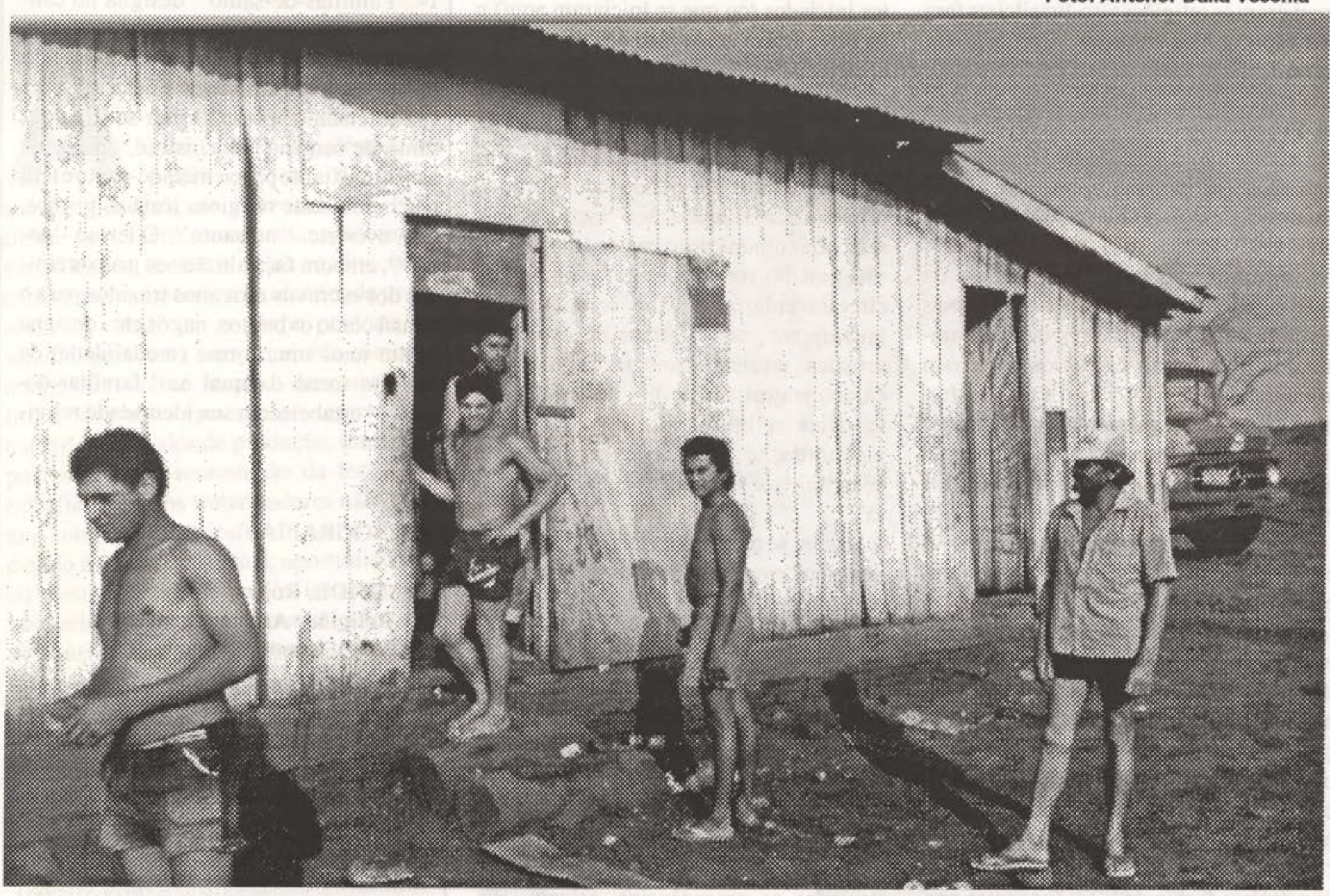

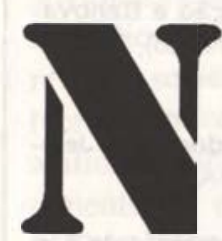
as últimas décadas, o processo de urbanização na região agricola de Ribeirão Preto (São Paulo) tem-se caracterizado por um forte crescimento demográfico tanto das cidades médias como daquelas cognominadas cidades-dormitórios, habitadas por trabalhadores rurais, conhecidos como bóias-frias. (1)

Estas últimas, além dos migrantes rurais da região, receberam, neste periodo, um contingente enorme de trabalhadores provenientesde outras partes do país, principalmente do nordeste, norte do Paraná e Vale do Jequitinhonha (M. Gerais). Através dos dados estatísticos, tem-se observado que estas cidades tiveram um crescimento demográfico, em alguns casos, su- perior à média do Estado, nos últimos anos. (2)

O objetivo deste artigo não é o de se concentrar na explicação do processo de urbanizaçãodesta região. Propõe-se analisar as cidades habitadas pelos trabalhadores rurais como espaços sociais, isto é, como espaços socialmente diferenciados.

Neste sentido, estas cidades serão entendidas como locais de reprodução desta força de trabalho, locais de realização de mercado de trabalho e também como locais controlados socialmente pelo poder da Usina ou grande fazenda, diretamente ou através de seus prepostos. E mais, serão entendidas enquanto espaços sociais, não como um todo homogêneo e sim diferenciado socialmente a partir da estrutura de classes e das diferenças entre os sexos masculino e feminino.

A grosso modo, estas cidades assemelham-se às vilas operárias sem contudo, existir a cessão da moradia por parte da empresa. Não obstante, além dos trabalhadores rurais, elas são habitadas por outros moradores pertencentes a outras categorias sociais. Assim sendo, em nosso entender, elas não podem ser consideradas cidades-dormitórios de bóias-frias, uma vez que esta denominação encobre as diferenças sociais que lhe subjazem e que são responsáveis também pela reprodução de relações de dominação sobre estes trabalhadores.

Geograficamente, estas cidades caracterizam-se por verdadeiros mundos fechados, cercados pelas muralhas vivas dos cafezais, laranjais ou canaviais da região. 
Em muitos casos, tanto o solo urbano quanto o rural pertencem aos donos das grandes usinas e fezendas, de tal forma que o próprio crescimento demográfico é limitado e controlado por eles. (3)

Historicamente, estas cidades surgiram no período da civilização cafeeira, nas primeiras décadas deste século. Preenchiam a função de complementaridade em relação ao mundo rural habitado por sitiantes, colonos, parceiros, etc. As pessoas que aí habitavam dedicavam-se às atividades comerciais, serviços e de pequenas fábricas. Possuiam alguns bancos e escolas. (4)

Com o processo de modernização agrária iniciado nos finais dos anos 60 , podese dizer que teve início o processo de passagem da civilização cafeeira para a civilização da usina.

Durante a civilização cafeeira, a configuração espacial era baseada na complementaridade entre cidade e campo no seio de uma divisão social do trabalho determinada pela produção dos meios de subsistência da maioria dos trabalhadores.

A passagem para a civilização da usina implicou um processo extremamente rápido, marcado pela destruição e desestruturação do universo cultural desta região. Pode-se dizer que a civilização da usina produziu um processo homogeneizador imposto sobre os destroços do antigo universo cultural dos excolonos, parceiros, sitiantes e fazendeiros de café.

As cidades dos bóias-frias, o mundo rural despovoado e coberto pelos milhares de hectares em cana, laranja e café são as duas faces deste processo.

Houve, em nosso entender, uma reestruturação espacial tanto em relação ao campo como em relação às cidades. Reestruturação não entendida somente a partir do despovoamento do campo e povoamento das cidades, mas também nos aspectos econômicos, sociais, políticos e culturais. Produziu-se uma nova "leitura deste espaço"' (a expressão é de Nestor G. Reis).

O traço mais marcante desta nova "leitura do espaço" no tocante ao campo foi o desaparecimento da paisagem e do "habitat" da civilização cafeeira. A homogeneidade espacial foi produzida em função da destruição (muitas vezes utili- zando-se máquinas) das casas dos excolonos parceiros, sitiantes, dos engenhos e até mesmo de antigas usinas. (5) À "leitura espacial" de antes, seguiu-se uma outra "leitura" definida pelas imensidões dos canaviais entrecortados pelos laranjais, cafezais, algodoais, onde, segundo um antigo morador " até mesmo os pássaros foram embora', e pelas cidades dos trabalhadores rurais. Estas assemelham-se a cidades fortificadas. Ao invés das pedras, o verde destes produtos contitui-se em suas próprias muralhas, em seus próprios limites.

Estas breves reflexões acerca da mudança espacial desta região são necessárias à compreensão destas cidades enquanto espaços sociais. Para isso, partimos da definição dada por Bourdieu, segundo o qual os espaços sociais são multidimensionais "...o espaço social é um espaço multidimensional, conjunto aberto de campos relativamente autônomos, isto é, mais ou menos fortemente e diretamente subordinados no seu funcionamento e nas transformações ao campo de produção econômica no interior de cada subespaço, os ocupantes das posições dominantes e das dominadas são frequentemente engajadas em lutas de diferentes formas"'.(6)

Esta definição sugere o abandono de muitas interpretações que consideram o econômicocomo oelemento absolutamente determinante das relações sociais. Ou seja, além das lutas de classes, outras ocorridas na horizontalidade das relações sociais não devem ser desprezadas, sob pena de não se captar a totalidade e a diversidade constitutivas da realidade social. (7)

Partindo destes pressupostos, analisase as diferenciações sociais destes espaços nos dois níveis: vertical e horizontal.

No tocante às diferenciações, há ainda que se considerar que estas cidades não são indistintas. Elas são, ao contrário, diferenciadas entre si.

A fim de facilitar a leitura deste trabalho, far-se-á primeiramente uma análise destas diferenças e, em seguida, daquelas referentesaos espaços sociais propriamente ditos:

a) cidades onde a Empresa cede a moradia aos seus trabalhadores. É o caso de Santa Ernestina, onde há uma verdadeira vila de operários qualificados da Usina. Os traba- lhadores rurais espalham-se por toda a malha urbana.

b) cidades onde há uma divisão social entre centro e vila. Incluem-se aí Altinópolis e Serrana. Os trabalhadores rurais concentram-se nas vilas.

c) cidades onde, além da separação entre centro e vila, há uma "favelização" das vilas, caracterizadas pela falta de infraestrutura urbana: rede de esgoto, ruas asfaltadas, etc. Inclui-se ai Guariba, onde está situado o Bairro João-de-Barro, habitado exclusivamente por bóias-frias.

Há que se considerar um aspecto comum a estas cidades (com exceção de Altinópolis): a construção de cômodos nos fundos dos quintais, de tal forma que quintais, varais, tanques ou até mesmo banheiros tornam-se espaços apropriados coletivamente por um grande número de moradores. Outro aspecto comum é o processo de autoconstrução das casas. Também aqui, observa-se a exceção de Altinópolis.

Nesta última cidade, a Vila dos trabalhadores rurais possui toda a infra-estrutura necessária: escolas, creches, inclusive a praça dos trabalhadores, com estátuas de colhedores de café, obras de um artista da região. As casas são construidas e financiadas pelo Sistema Nacional de Habitação e os terrenos são vendidos pela prefeitura. Não há aí, a "favelização" constatada em outras cidades.

As razões desta diferenças podem ser explicadas através de três ordens de fatores:

a) Muitos dos moradores da vila são antigos colonos ou mesmo sitiantes. Estes puderam, graças a algum pecúlio, comprar suas moradias.

b) Trata-se de uma cidade, historicamente, dominada pelo poder dos descendentes dos antigos coronéis, fazendeiros de café. A concentração dos trabalhadores na cidade não contribuiu, ao longo destes últimos anos, para uma mudança do processo de sustentação política das classes dominantes. Na verdade, houve a criação de novas formas de controle e a reprodução de práticas personalistas e clientelísticas de dominação, através de investimentos em equipamentos coletivos na vila dos trabalhadores que possui além dos itens já citados, centros de lazer com piscinas, quadras de esporte, etc. Os descendentes 
dos antigos coronéis disputam hoje seus votos de apoio político junto aos trabalhadores rurais da vila, ao contrário de seus ascendentes que os disputavam nas fezendas. Houve, ipso facto, uma transferência espacial do controle político, o que dificulta a organização político-sindical deste trabalhadores.

A "ausência da miséria", o "bom nível de vida dos trabalhadores", "a boa qualidade da merenda escolar fornecida pela prefeitura", a "limpeza da vila" são frases que compõem o discurso dos representantes do poder local, sendo, portanto, ingredientes da ideologia dominante que procura, ao ressaltar a "ordem e a limpeza do vila", escamotear a exploração e controle exercidos sobre os trabalhadores.

c) A moradia dos grandes fazendeirosé na cidade. Este fato permite a continuidade das relações personalistas e de reconhecimento por parte dos patrões de seus empregados, já que o crescimento da cidade é controlado por eles, através do poder local, uma vez que possuem a propriedade do solo urbano e rural que circunda a cidade com seus cafezais.

Estas diferenças intercidades além de revelarem que elas não podem ser tomadas como blocos homogêneos sob a rubrica de cidades-dormitórios, apontam para um maior aprofundamento destas reflexões.

Assim sendo, pode-se falar em habitus de classes produzidos nestas cidades. Ainda, segundo Bourdieu, "falar de habitus de classe... (significa compreender os individuos dentro da) sua posição presente e passada na estrutura social que os individuos, entendidos como pessoas físicas, transportam com eles em todo o tempo e lugar, sob a forma de habitus. Os individuos vestem os habitus com hábitus, assim como o hábito faz o monge, isto è, faz a pessoa social, com todas as disposições que são, ao mesmo tempo, marcadas da posição social, e portanto, da distância social entre as posições objetivadas, entre as pessoas sociais conjunturalmente aproximadas (no espaço físico que não é o espaço social), e a reafirmação dessa distância e das condutas exigidas para "guardar suas distâncias' ou para manipulá-las estratégica, simbólica ou realmente, reduzilas... aumentá-las ou simplesmente mantêlas... "guardando seu lugar', ... enfim, ficando no seu lugar." (8)
As definições de espaço social e habitus são fundamentais à compreensão dos "lugares”, das disposições sociais das pessoas nestas cidades tanto no sentido vertical como no horizontal.

No que tange a Altinópolis, os habitus dos grandes fazendeiros são aparentes e vistos pelos demais habitantes da cidade. O mesmo não ocorre com os grandes usineiros e proprietários das indústrias de sucos de laranja que habitam as cidades médias ou as grandes metrópoles como São Paulo e Rio de Janeiro. Nas cidades dominadas por estes últimos, o controle é, em muitos casos, camuflado pela não objetividade da estruturação de seus hábitus de classe.

Da mesma forma que o usineiro não aprece nas relações do espaço produtivo, ele também não aparece nas relações do espaço reprodutivo. Não obstante, a não aparência, o controle político e social existe nos dois espaços disfarçado sob o envelope de seus mediadores. (9)

Pradópolis a Américo Brasiliense seriam exceções a esta não aparência. Pradópolis é conhecida na região, como sendo o quintal da Usina. Além do poder local ser controlado diretamente pelos usineiros, estes limitam também o crescimento da cidade, impedindo o estabelecimento de migrantes e controlando diretamente a reprodução dos trabalhadores e o mercado de trabalho. A cidade de Américo Brasiliense, em sua última gestão, teve como prefeito um usineiro. (10)

Nas demais cidades, o mercado de trabalho écontrolado diretamentepelos agenciadores, gatos e representantes do escritório das empresas.

No que tange à verticalidade das relações sociais no interior destas cidades, a separação social entre centro e vila ou bairros está associada à constituição da estrutura social. Em muitas delas, além das vilas ou bairros serem os "lugares" dos bóias-frias, são também os "lugares" dos outros, da gente vinda de fora (referênciaaosnordestinos, mineirose paranaenses que se dirigiram em grande número para estas cidades desde o início do processo modernizador da agricultura).

Em Dobrada e Guariba, os "lugares" dos bóias-frias são a Vila-de-barro e o João-de-barro, respectivamente. Denominações dadas pelos moradores antigos aos bairros dos recém-chegados.

Massa heterogênea, do ponto de vista cultural, mas tratada homogeneamente pelos habitantes destas cidades. Eram tratados como um bando de invasores, gente suja, portadora de maus costumes, genteviolenta. Os estigmas qualificavam-nos como baianada, mineirada, peãozada, gente dos países (sic) do norte. Habitantes dos barracos de barro autoconstruídos, responsáveis pela desordem urbana e pelo enfeamento das cidades com suas sujeiras. (11)

A seguir, o depoimento de um antigo morador de Guariba sobre o surgimento do bairro João-de-barro revela os traços estigmatizadores constitutivos dos "olhares" do "nós" em relação aos " outros",

"Os ex-colonos das fazendas e os nordestinos foram os habitantes da vida Garavelho. Posteriormente, esta vila foi sendo duplicada e surgiu uma parte mais alta da cidade, o conhecido João-de-barro. Este nome se deve porque as primeiras casas eram feitas de barro, barroca, este sistema... não a taipa tradicional de São Paulo... aquele pilão. Eles construíam em barro mesmo, lajotas de barro, madeira entrelaçada e recheada de barro. Deve ser este o sistema de construção lá do norte, nordeste... de primeiro, predominava uma migração de italianos, portugueses e outros europeus. Os colonos eram latinus... então, eles tinham um sistema de vida, de alimentação que trouxeram da terra deles, agora, chegando esta leva de mineiros, baianos, eles traziam um tipo de vida diferente. Havia um choque, e até hoje, aumentou a criminalidade na cidade. É uma cidade violenta, mas os crimes acontecem entre eles. É um povo estranho."

Povo estranho. Povo das casas de barro. Gente fora do lugar. Gente desenraizada. Produtores de violência entre eles. Como na feliz expressão de Sérgio Adorno, ao referir-se aos crimes em alguns locais da cidade de São Paulo, há aí a "violência entre os iguais", na cidade onde predomina o "código do sertão urbano". (12)

Atualmente, o barro foi encoberto por uma fina camada de reboco e pintado. Aparentemente, ele não mais existe. Esconde-se, no entanto, sob uma fina argamassa do "estilo paulista" de se construir casas. O João-de-barro chama-se hoje, Bairro Alto e Princesa Isabel. No entanto, 
não perdeu suas marcas, seus estigmas. Nas palavras de uma moradora do bairro, "mudou o nome, mas não adiantou nada". Isto demonstra que as marcas sociais de seus moradores, marcas que acompanham suas trajetórias de nordestinos, baianos, gente de fora, imprimem ao lugar onde vivem, ao espaço físico onde construíram suas casas, a objetivação de suas próprias marcas e posição social.

Além desta divisão social entre "nós" e "os outros", há entre os próprios trabalhadores rurais uma redivisão entre eles e os migrantes, os " peões provisórios" que chegam no periodo da safra. Estes são alojados em quartos, ou cômodos nos fundos de quintais, ou ainda, nas pensões. Reproduzem em relação a eles os mesmos estigmas: peãozada, mineirada, gente de fora. Também sobre eles recai um maior controle policial, havendo casos de explusão da cidade através da polícia em comum acordo com os gatos que os trouxeram. Se estas marcas existem entre os próprios iguais, em relação aos habitantes do centro, elas são ainda maiores, configurando estes espaços sociais como multidimensionais, segundo a expressão de Bourdieu.

Este caráter multidimensional pode ser também observado no tocante a uma outra divisão dos espaços sociais: os espaços masculinos e femininos.

O espaço das mulheres é principalmente o interior das casas. Ai desdobramse na execução das tarefas domésticas, quase sempre desempenhadas à noite, quando chegam do trabalho ou pela madrugada, antes de se dirigirem ao trabalho.

Quanto aos homens, além da casa, onde raramente desempenham alguma tarefa, eles estão presentes nos bares e botecos, existentes em grande quantidade nas vilas e bairros.

A casa não chega a ser um interior propriamente dito. É um ponto de reunião. Ai se come, dorme e a mulher realiza as tarefas domésticas. (13) Excetuados estes momentos, as crianças estão nas ruas, espaços de brinquedos, homens e mulheres estão no eito, ou os homens estão nos botecos. Para a mulher, fora do momento do trabalho no espaço produtivo, a casa é o espaço do seu enclausuramento para o trabalho doméstico de limpar, passar, cozinhar.

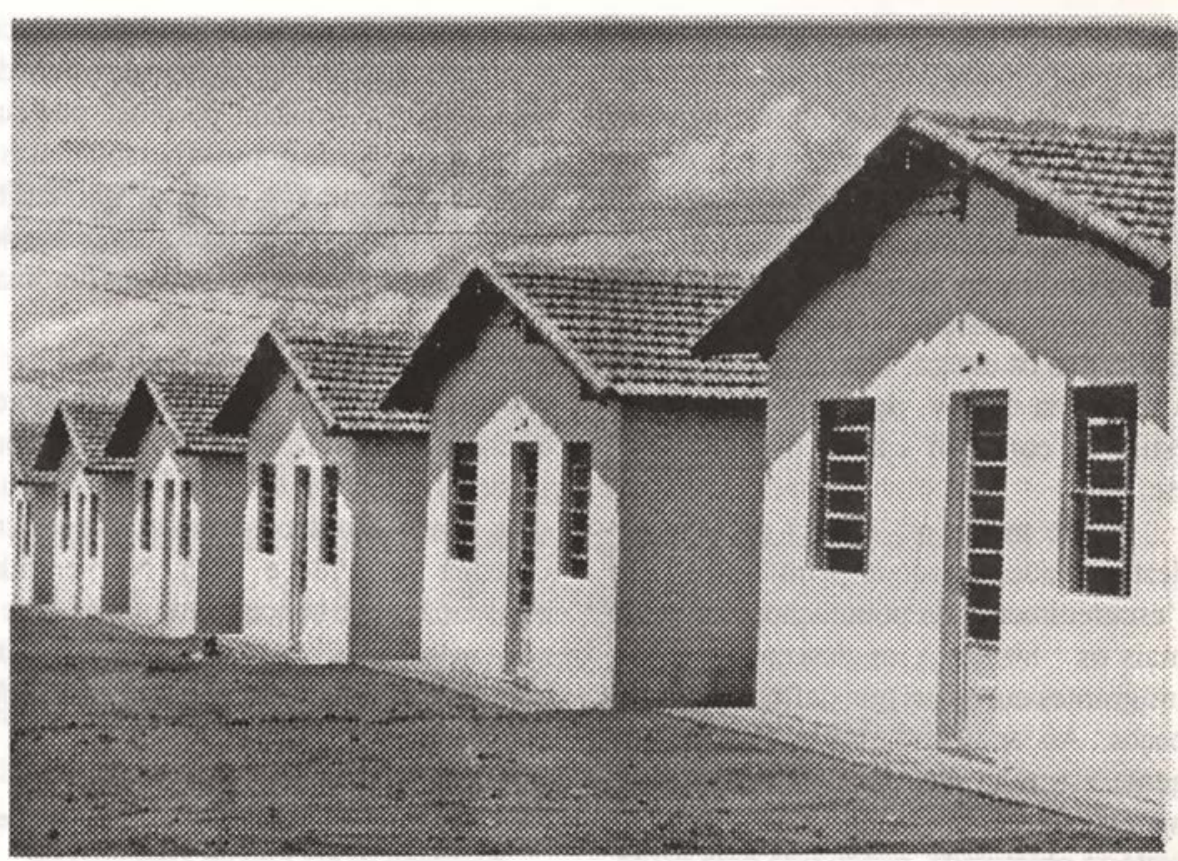

O bairro ou a vila, aos poucos vai se dividindo em espaços masculinos e femininos. Os botecos são, prioritariamente, locais masculinos. As mulheres que os frequentam são faladas.(14)

As mulheres, pelo fato de terem sido transformadas em donas de casa num certo momento do dia, perderam o saber da indústria doméstica, já que nas cidades não dispunham mais da base material da produção de seus meios de subsistência. Suas condutas econômicas e as estruturas de suas consciências temporais foram radicalmente transformadas pela monetarização dos rendimentos do grupo familiar. (15)

Nas cidades, os espaços femininos se resumem, então, a casa, aos locais onde compram alguns produtos necessários à reprodução do grupo familiar (supermercados, vendas, lojas, feiras, farmácias, etc.). Alguns produtos, porque o nível de vida destes trabalhadores é muito baixo. Pelos depoimentos, conclui-se que a grande preocupação é não passar fome. Além destes espaços, as mulheres frequentam as igrejas e, algumas delas, os sindicatos.

Os bailes, principalmente para jovens solteiros, são o local de encontro. Nestes bailes, não se dançam mais o sapateado, a catira. Os forrós, resultado de uma espécie de homogeneizaçãocultural, predominam. Aí, muitas vezes, ocorrem violências entre os próprios iguais. As festas que ocorri- am no mundo rural, no mundo de antes, praticamente acabaram. Em algumas cidades, no entanto, há ainda a conservação da festa de Reis, da Folia de Reis com integrantes de antigas folias existentes no mundo rural.

Contudo, a participação nestas festas refere-se mais às pessoas mais velhas, uma vez que os jovens já sofreram todo o processo aculturador da indústria cultural, principalmente através da televisão e rádio.

Pode-se afirmar, a partir de tais considerações que ocorreram dois processos simultâneos no bojo das transformações nesta região.

Primeiramente, houve um processo desestruturador do espaço físico e social, seguido de uma homogeneização tanto física quanto social. O resultado foi $o$ processo de restauração social e cultural.

Em segundo lugar, houve também a produção de um novo modo de vida tanto no campo quanto nas cidades. Nestas, recriou-se a dicotomia de classes e de gênero, redefinindo os espaços sociais enquanto espaços de classes, de separação entreos sexos e de diferenças no interior da própria classe. Portanto, estas cidades são constituidas de espaços sociais multidimensionais marcados por diferenças verticais e horizontais.

A civilização da usina produziu um novo modo de vida, isto é, uma nova 
sociabilidade e novas relações no cotidiano destes homens e mulheres inseridos em relações de classes e de gênero e também de etnia, se se pensar que boa parte destes trabalhadores não é descendente de "latinus", segundo o depoimento mencionado em linhas atrás, mas ao contrário, são negros, mulatos, "gente do norte", Enfim são os outros. Outros que possuem a trajetória da cor, da regionalidade, do estilo de construir casas em "barroca" etc.

Deste modo, a "leitura do espaço" destas cidades apreende, primeiramente, 0 " "escurecimento da população". Não são mais os "'latinus", os descendentes dos imigrantes europeus que definem seus espaços. Ao contrário. Estas "levas" de gente estranha passam a fazer parte da história incorporada juntamente com a história objetivada, produzida pela usina. (16) Além deste "escurecimento", as assimetrias produzidas quanto aos gêneros masculino e feminino, e aos trabalhadores migrantes temporários, fecham o círculo da vida existente no interior destas cidades, verdadeiros mundosfechados pelo verde das plantações que as circundam.

Espaços com subespaços sociais marcados pela desvalorização simbólica em virtude da desvalorização corporal dos seus próprios moradores.

São estas considerações que nos conduzem afirmar que a denominação de cidades-dormitórios, ao impingir a marca de conjuntos homogêneos a estas cidades, camufla as diferenciações produzidas no interior da mesma classe dominada e o poder político e social da Empresa exercido através do poder local, logo da esfera do público. Esta situação permite, por sua vez, a recriação de práticas personalistas e coronelistas através da confusão entre público e privado e da recriação de novas formas de controle social sobre os dominados.

É neste contexto que se pode explicar o porquê das greves destes trabalhadores terem ocorrido no espaço das cidades com piquetes e, em alguns casos com destruições, como aconteceu com as greves em Guariba em 1984 e 1985. Na verdade, estas cidades ao concentrarem o poder e 0 controle, elas transformam-se, em contrapartida, em espaços políticos de ação e resistência.

\section{* Maria A. M. Sllva 6 Professora junto ao Dpto. de Sociologla da FCL/UNESP-Araraquara/SP.}

\section{NOTAS E REFERÊNCIAS \\ BIBLIOGRÁFICAS}

(1) O processo de modernização agrária nesta regiāo foi acompanhado do êxodo rural causado pela expulsão dos trabalhadores residentes nas fezendas, pela dissolução das formas de trabalho assentadas na parceria e arrendamento e pela extinção dos sitiantes.

(2) Segundo os resultados do censo demográfico de 1991, estas cidades registraram um grande crescimento populacional. Em 1980, a população de Américo Brasiliense era de 11.871 habitantes. Em 1991, esta cifra se eleva para 20.015. Para as outras cidades, estes números são, para este periodo: Barrinha contava em 1980, com 12.563 habitantes e em 1991, com 18.924; em Guariba, a população passa de 18.893 para 28.743 habitantes; Dobrada, de 4.385 para 6.901; Santa Emestina, de 3.503 para5.608; Serrana, de 14.336 para23.151; Pitangueiras, de 18.607 para 29.488; Pontal, de 16.742 para 22.691. Entre as cida-

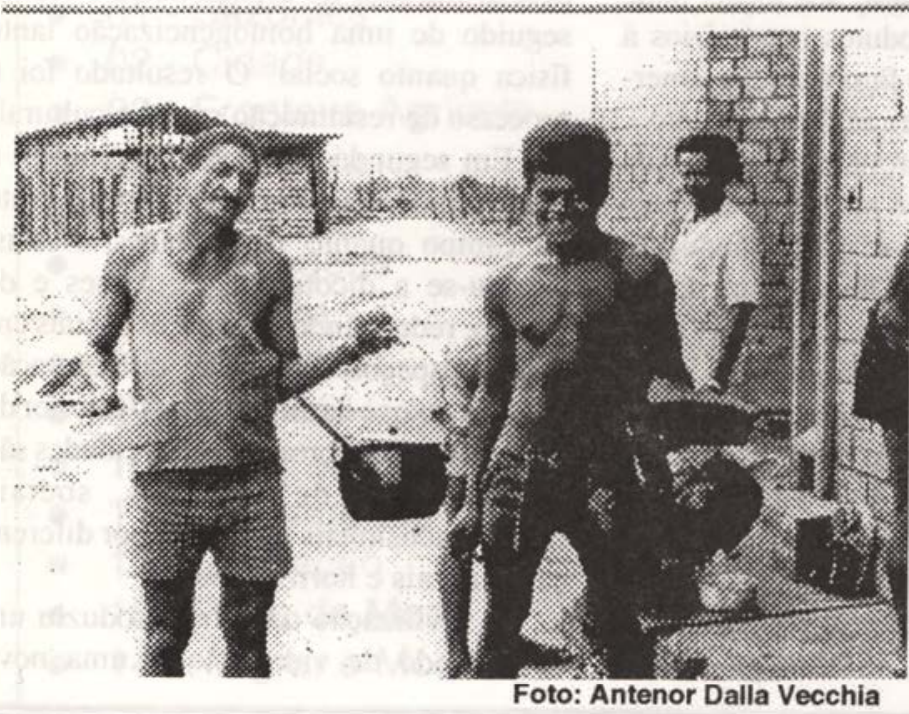
des com menor taxa de crescimento, destaca-se Altinópolis, cuja população passa de 12.744 para $13 . .521$ habitantes $e$ Pradópolis que em 1980 contava com 7.837 habitantes, passaaterem 1991,9.865 habitantes. Nestas duas cidades, há um controle do aumento dapopulaçãopelaempresa, através dapropriedade do solo urbano e do controle da imigração.

(3) Este é o caso de Altinópolis, cercada pelos cafezais dos grandes fazendeiros. Em virtude do poder local ser sucessivamente controlado por eles, a cidade não possui espaço físico para crescer, uma vez que eles não desapropriam as áreas ocupadas pelos cafezais para a construção de moradias urbanas.

(4) Ver a respeito da sociabilidade desenvolvida nestas cidades, principalmente, aos sábados, com a presença de muitos habitantes da área rural com suas inúmeras carroças $\theta$ charretes, Monbeig, P. Pionniers et planteurs de S. Paulo. Librairie Armand Colin, Paris, 1952.

(5) Este processo guarda fortes lembranças com o exemplo histórico da acumulação primitiva descrita por Marx. Com as enclosures, houve também o processo da homogeneização do espaço após a desestruturação do espaço anteriormente existente.

(6) Bourdieu, P. Espace social et génese de classe. In Actes de la Recherche números 52/53, juim, 1984, pgs. 9-10.

(7) Silva, M.A.M.; Ferrante, V.L.S.B. Bóias-Frias: vida, trabalho e lutas. 1987.

-- Silva, M.A.M. Mulheres Bóias-Frias. Natureza ou Anomalia. 1989.

- Silva, M.A.M. Migrantes temporários na região de Ribeirão Preto. S.Paulo, 1988.

(8) Bourdieu, P. Esboço de uma teoria da prática. In Ortiz, R. (org.) e Fernandes, F. (coord.) Pierre Bourdieu. Coleção grandes cientistas sociais. Ed. Ática, num. 39, S. Paulo, 1983, pg.75.

(9) No espaço produtivo, o controle é exercid j por intermédio dos feitores, fiscais e agenciadores da força de trabalho. As punições variam desde a proibição de "subir no caminhão para trabalhar", até as suspensões temporárias (ganchos! a listas negras (proibições de trabalhar até três đ:ios). (10) O controle exercido pelos usineiros sobre a reproduçāo dos trabalhadores rurais é objeto de dissertação de mestrado de Grasiela Lima - PósGraduação em Sociologia urbana e rural - FCL UNESP-Araraquara.

(11) Sobre o sujo, a sujeira, ver Da Matta, R. Carnavais, Malandros e heróis. Zahar Ed., 4a. edição, R. de Janeiro, 1983.

(12) Este depoimento e o de muitos outros habitantes do centro da cidade foram confirmados por um levantamento feito na delegacia de polícia local acerca dos crimes, agressões, lesões corporais ocorridos em Guariba, cuja grande maioria se refere aos habitantes do João-de-barro e a violência ocorre no seu próprio interior. A mesma situação de "violência entre os iguais" foi constatada por Serrana.

(13) Perrot, M. Os excluídos da história. Ed. Paz e Terra, R. de Janeiro, 1988, pg. 221. A autora retrata a mesma situação vivenciada pelas muIheres francesas no séc. XIX.

(14) Nestas cidades, os botecos são, essencialmente, espaços masculinos. Exceção feita a Guariba, onde muitas mulheres frequentam os bares do bairro onde residem. Em geral, são mulheres solteiras, separadas e sós. Nas demais cidades, o preconceito contra as mulheres que frequentam os botecos é muito grande.

(15) Sobre estas questōes, em nivel teórico, ver Bourdieu, P. Algérie 60...Structures économiques et structures temporales. Les Éditions du Minuit, Paris, 1977, especialmente, o capitulo primeiro.

(16) Bourdieu. P. Le mort saisit le vif. In Actes de la Recherche, núms. 32/33, avil/juin, 1980. 